学術論文

\title{
多自由度球面同期アクチュエータの許容電流に着目したトルク領域法
}

\section{Evaluation Method for Multi-Degree-of-Freedom Spherical Electromagnetic Synchronous Actuators under Allowable Current}

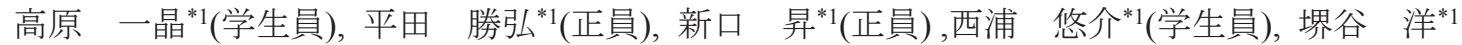

\author{
Kazuaki TAKAHARA (Stu. Mem.), Katsuhiro HIRATA (Mem.), Noboru NIGUCHI (Mem.), \\ Yusuke NISHIURA (Stu. Mem.), Yo SAKAIDANI
}

\begin{abstract}
Multi-degree-of-freedom (multi-DOF) actuators have been developed for the fields of robotics and industrial machinery. We have proposed an evaluation method for the multi-DOF actuators based on a torque equation and singular value decomposition under constant power. However, the evaluation method does not take into account a current density. In this paper, we propose a new evaluation method considering an allowable current. Finally, the static torque characteristics of a previously developed multi-DOF actuator is evaluated using the proposed evaluation method.
\end{abstract}

Keywords: multi degree of freedom, spherical actuator, static characteristics, evaluation.

(2016 年 11 月 24 日受付， 2017 年 4 月 3 日再受付)

\section{1 緒言}

現在，産業用ロボットなどで用いられているリンク 機構では，多自由度の動作を実現するために，その自 由度に応じて 1 自由度アクチュエータを組み合わせて いる[1]。その際，エンドェフェクタ付近のアクチュ エータの質量がベース付近のアクチュエータに対して 負荷となるため, ベースに近付くにつれてアクチュ エータが大型化する傾向にあり，力制御等の高精度な 制御における問題が指摘されている[2]。これらの課題 の解決方法として, 球面駆動可能なアクチュエータが 注目されている。多自由度球面アクチュエータを用い ることで，搭載するアクチュエータの数を削減でき, 機構の小型化が期待できる。また, 従来のシリアルリ ンク機構では, 複数台のアクチュエータの駆動軸の交 点を一致させるなどの工夫がなければ，逆運動学を一 意に解くことができない[3]。しかし, 球面駆動可能な アクチュエータを用いることで，各自由度の回転軸は 常に一点で交わるため, 上記の問題は生じない。した がって, 逆運動学を幾何学的に解くことが可能となり, 制御の簡素化による高速化，高度化が期待できる。

以上の利点から多自由度球面アクチュエータの産 業用ロボット等への応用が期待されており, 研究・開

連絡先 : 高原 一晶, $\bar{T} 565-0871$ 大阪府吹田市山田丘 2-1, 大阪大学大学院 工学研究科 知能 - 機能創成工学専攻, e-mail: kazuaki.takahara@ams.eng.osaka-u.ac.jp ${ }^{*}{ }^{1}$ 大阪大学
発が盛んに行われている。電磁力を利用した多自由度 球面アクチュエータは, 同期モータ, ステッピングモー タ，誘導モータといった様々な駆動原理を利用したア クチュエータが報告されている[4-10]。特に, 球面同期 アクチュエータは任意軸周りにトルクを制御可能な卜 ルク発生式が開発されており，その制御性の高さから 多くの研究機関が開発に取り組んでいる[4-8]。

しかし，球面同期アクチュエータは任意の姿勢，任 意の軸周りのトルクを実現できるという特長を有する が，可動範囲全域に渡って各姿勢，各方向のトルクを 評価することは困難であり，単軸周りの局所的な評価 に留まっている[5-9]。著者らはある姿勢における任意 軸周りの静特性を評価する手法として，定電力下にお けるトルク領域法を提案した[11]。この手法は定電力 下で，任意の可動子姿勢において発生可能なトルクの 領域をトルク発生式から求める手法である。この手法 により, 球面同期アクチュエータの任意の軸周りにト ルクを発生できる特長を活かした評価が可能となった が，電力の制限のみに着目しており，アクチュエータ 自体の許容電流は考慮されていない。実際のアクチュ エータでは巻線の絶縁被膜の保護などの観点から許容 電流を定めるため, 巻線の線径や泠却条件が異なる場 合は許容電流に着目した評価が必要となる。

そこで本稿では，許容電流に着目した際のトルク領 域をトルク発生式から求め, 定電力下におけるトルク 領域と比較する。それにより，定電力下のトルク領域 では考慮できていなかった静特性について検証する。 


\section{2 球面同期アクチュエータのトルク発生式}

本稿で扱う多自由度球面同期アクチュエータの概 念図を Fig. 1 に示す。球状の可動子の表面に複数の球 款状の永久磁石を配置し, 固定子に巻線を放射状に配 置している。可動子と同期するように巻線に多相の電 流を印加し, 多自由度の回転を実現している。なお, 巻線に印加する電流の相数はアクチュエータによって 異なり, 4 相励磁から 96 相励磁まで報告されている [4-8]。

次に, 本稿で用いるトルク発生式について述べる[4]。 ここで, 各巻線で生成された磁界は他の巻線で生成さ れた磁界に影響を及ぼさず，独立にアクチュエータの トルクに寄与すると仮定すると, 多自由度の球面同期 アクチュエータのトルク発生式は式(1)で表される。

$$
\left[\begin{array}{c}
\tau_{X} \\
\tau_{Y} \\
\tau_{Z}
\end{array}\right]=\left[\begin{array}{cccc}
K_{X}\left(\boldsymbol{p}_{1}\right) & K_{X}\left(\boldsymbol{p}_{2}\right) & \cdots & K_{X}\left(\boldsymbol{p}_{n}\right) \\
K_{Y}\left(\boldsymbol{p}_{1}\right) & K_{Y}\left(\boldsymbol{p}_{2}\right) & \cdots & K_{Y}\left(\boldsymbol{p}_{n}\right) \\
K_{Z}\left(\boldsymbol{p}_{1}\right) & K_{Z}\left(\boldsymbol{p}_{2}\right) & \cdots & K_{Z}\left(\boldsymbol{p}_{n}\right)
\end{array}\right]\left[\begin{array}{c}
i_{1} \\
i_{2} \\
\vdots \\
i_{n}
\end{array}\right]
$$

ここで， $\tau_{X}, \tau_{Y}, \tau_{Z}$ はそれぞれ $X$ 軸， $Y$ 軸， $Z$ 軸周りの 電流卜ルク， $i_{1}, i_{2}, \ldots, i_{n}$ は各相の巻線電流, $K_{X}, K_{Y}$, $K_{Z}$ はそれぞれ $X$ 軸, $Y$ 軸, $Z$ 軸周りの各相巻線におけ るトルク定数である。このトルク定数で構成された行 列をトルク定数行列と呼ぶ。 $\boldsymbol{p}$ は各相巻線と可動子と の位置関係を示し, 可動子の姿勢を変数に持つ。式(1) を用いて任意の姿勢における電流トルクを設定するこ とにより, 各相の電流值を求めることができる。式(1) の右辺はそれぞれ相数と同数のベクトルの線形結合で 表すことができる。簡単のために, 例として 3 相の電 流を入力寸る 2 自由度のトルク発生式を分解寸ると, 式(2)，(3)のようになる。ここで，2 自由度の場合は, 式(1)の $Z$ 軸周りの成分を除いたトルク発生式となる。

$$
\begin{aligned}
& {\left[\begin{array}{l}
\tau_{X} \\
\tau_{Y}
\end{array}\right]=\left[\begin{array}{lll}
1.5 \cos \left(\frac{\pi}{3}\right) & 3 \cos \left(\frac{\pi}{18}\right) & 2 \cos \left(-\frac{11}{18} \pi\right) \\
1.5 \sin \left(\frac{\pi}{3}\right) & 3 \sin \left(\frac{\pi}{18}\right) & 2 \sin \left(-\frac{11}{18} \pi\right)
\end{array}\right]\left[\begin{array}{l}
i_{1} \\
i_{2} \\
i_{3}
\end{array}\right]} \\
& =\boldsymbol{k}_{1} i_{1}+\boldsymbol{k}_{2} i_{2}+\boldsymbol{k}_{3} i_{3} \\
& \boldsymbol{k}_{1}=\left[\begin{array}{l}
1.5 \cos \left(\frac{\pi}{3}\right) \\
1.5 \sin \left(\frac{\pi}{3}\right)
\end{array}\right], \quad \boldsymbol{k}_{2}=\left[\begin{array}{l}
3 \cos \left(\frac{\pi}{18}\right) \\
3 \sin \left(\frac{\pi}{18}\right)
\end{array}\right] \\
& \boldsymbol{k}_{3}=\left[\begin{array}{l}
2 \cos \left(-\frac{11}{18} \pi\right) \\
2 \sin \left(-\frac{11}{18} \pi\right)
\end{array}\right]
\end{aligned}
$$

ベクトル $\boldsymbol{k}_{1}, \boldsymbol{k}_{2}, \boldsymbol{k}_{3}$ は単位電流を印加した際のトルク

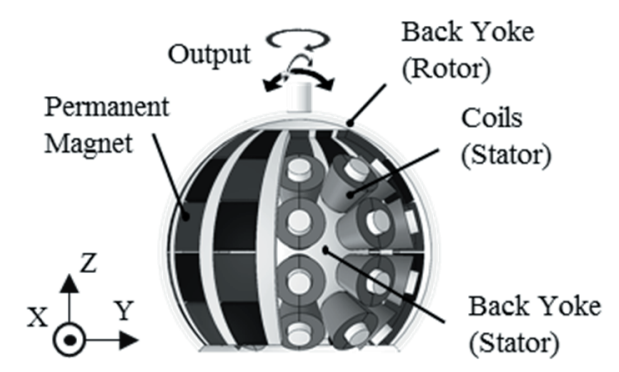

Fig. 1 Basic structure of spherical actuators.

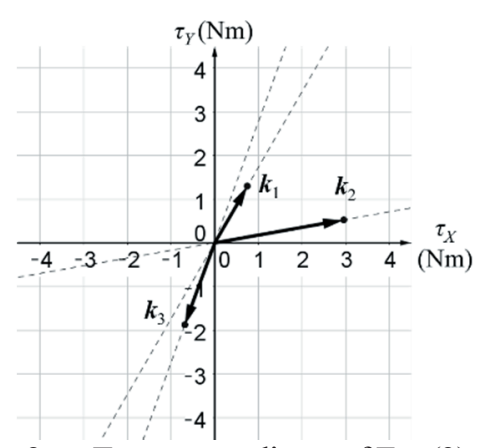

Fig. 2 Torque coordinate of Eq. (3).

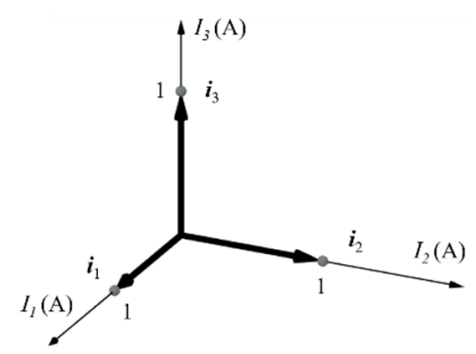

Fig. 3 Current coordinate.

定数ベクトルと呼ばれ，大きさはトルクの大きさを表 し，向きはトルクが作用する軸を表す。このトルク定 数ベクトル $\boldsymbol{k}_{1}, \boldsymbol{k}_{2}, \boldsymbol{k}_{3}$ を Fig. 2 に示し，この空間を卜 ルク座標系と定義する。また, トルク定数ベクトル $\boldsymbol{k}_{1}$, $\boldsymbol{k}_{2}, \boldsymbol{k}_{3}$ を発生するために必要な電流を Fig. 3 に示し, この空間を電流座標系とする。電流ベクトルの各要素 は，各相に印加する電流を意味する。ここで，トルク 定数行列は電流座標系からトルク座標系への線形写像 を意味し, トルク定数行列の階数が $m$ であれば, $m$ 次 元上の任意のトルクベクトルを表現可能となる。すな わち, 式(2)において, 階数は 2 であるため 2 次元上の 任意のトルクベクトルを表現できることがわかる。

\section{3 トルク領域}

第 2 節でトルク定数行列は電流座標系からトルク座 標系への線形写像を意味し，その階数に応じた次元の トルクベクトルが表現可能であることを述べた。しか し, 実際のアクチュエータでは供給される電力の制限 
や，巻線の絶縁被膜の保護などによる電流の制限のた めに電流座標上で領域が定義され，その射影であるト ルクがトルク座標上の対応する領域に制限される。そ のため, 本節では定電力下でのトルク領域と, 許容電 流を定めた際のトルクの領域をトルク発生式より導出 する。そして，このトルク領域を用いて各可動子姿勢 での静トルク特性を定義する。

\section{1 定電力下でのトルク領域}

定電力下におけるトルク領域は，トルク発生式にお けるトルク定数行列を特異值分解することによって, 各姿勢における任意方向に発生可能なトルクの領域を 算出する。トルク発生式を元にトルク領域の導出方法 を記す[11]。

まず，電力に制限を与えた場合の電流座標上での 領域について考える。 $n$ 相の球面アクチュエータに 入力された電力が銅損と等しいと仮定すると式(4) が得られる。

$$
R\left(i_{1}^{2}+i_{2}^{2}+\cdots+i_{n}^{2}\right)=\text { const } .
$$

ここで, $R$ は巻線抵抗であり, 各巻線の巻線抵抗は 同じとしている。例として 3 相の場合を考えると, 電流の領域は Fig. 4 のような球体となる。この電流 の領域を式(2)のトルク定数行列によってトルク座 標上に射影寸ると, Fig. 5 に示す楕円の領域となる。 原点とこの領域内の点を結ぶベクトルが，電流を印 加することによって発生可能なトルクを表す。この 2 自由度の場合の定電力下でのトルク領域の導出に ついて記す。例として式(2)の 2 行 3 列のトルク定数 行列 $\boldsymbol{K}$ について考えると, 式(5)で表される $\boldsymbol{K}$ の特異 值分解が可能である。

$$
\boldsymbol{K}=\left[\begin{array}{ll}
\boldsymbol{u}_{1} & \boldsymbol{u}_{2}
\end{array}\right]\left[\begin{array}{ccc}
\sigma_{1} & 0 & 0 \\
0 & \sigma_{2} & 0
\end{array}\right]\left[\begin{array}{lll}
\boldsymbol{v}_{1} & \boldsymbol{v}_{2} & \boldsymbol{v}_{3}
\end{array}\right]^{T}
$$

ここで, $\boldsymbol{u}_{1}, \boldsymbol{u}_{2}$ は左特異ベクトル， $\sigma_{1}, \sigma_{2}\left(\sigma_{1} \geq \sigma_{2}\right)$ は特異值, $v_{1}, v_{2}, v_{3}$ は右特異ベクトルである。 $\boldsymbol{u}_{1}$, $\boldsymbol{u}_{2}$ は長軸, 短軸の向き, $\sigma_{1}, \sigma_{2}$ は長軸, 短軸の長さ を表す。また, $\boldsymbol{v}_{1}, \boldsymbol{v}_{2}$ は長軸, 短軸のトルクベクト ルを発生させるために必要な電流を表す。一定電力 の条件下で長軸, 短軸のトルクベクトルを補間する と, トルクベクトルの軌跡は次式で表される。

$$
\left[\begin{array}{c}
\tau_{X} \\
\tau_{Y}
\end{array}\right]=\sigma_{1} \boldsymbol{u}_{1} \cos \theta+\sigma_{2} \boldsymbol{u}_{2} \sin \theta
$$

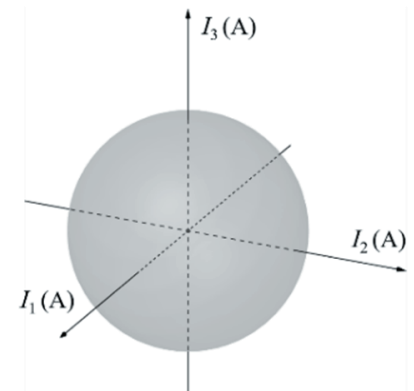

Fig. 4 Current area under constant power.

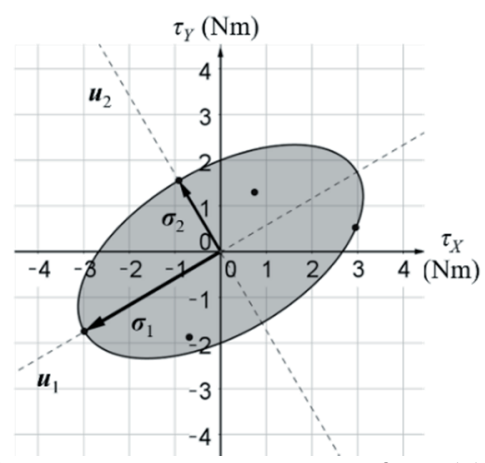

Fig. 5 Torque output area of Eq. (8).

ここで, $\cos \theta, \sin \theta$ は補間係数である。式(6)より，2 自由度球面同期アクチュエータが一定電力下で発生可 能なトルクの領域は, Fig. 5 の例に示寸ように原点を 中心として長軸を最大トルクベクトル，短軸を最小ト ルクベクトルとした楕円となる。トルク定数行列は可 動子姿勢によって変化するため, トルク領域も可動子 姿勢によって変化する。また， 3 自由度の場合は $\boldsymbol{Z}$ 軸 成分が追加され，トルク領域は楕円体となる。

\section{2 許容電流に着目したトルク領域}

次に，許容電流に着目した際のトルク領域をトルク 発生式から求める。まず, 許容電流を定めた際の電流 座標上での領域について記す。 $n$ 相の場合の許容電流 は以下の式(7)で定義する。

$$
\left|i_{j}\right|=i_{\max } \quad(j=1,2, \cdots, n)
$$

ここで, $i_{k}$ は各相の電流であり, $i_{\max }$ は許容電流である。 例として 3 相の場合を考えると, 電流の領域は Fig. 6 のような立方体となる。この電流の領域を式(2)のトル ク定数行列によってトルク座標上に射影すると, Fig. 7 の例に示すような多角形の領域となる。原点とこの領 域内の点を結ぶベクトルが，電流を印加することに よって発生可能なトルクを表す。すなわち, このトル ク領域では $X$ 軸回りに最大約 $3 \mathrm{Nm}$ のトルクを発生で きる。この 2 自由度の場合のトルク領域の導出につい 
て記す。任意の相を 1 つ選択し, その他を定数とする と，トルク座標上で式(8)の線分の式を得る。

$$
\begin{aligned}
\boldsymbol{P}_{j}=\boldsymbol{k}_{j} i_{j}+\sum_{l=1}^{n}\left(1-\delta_{j l}\right) \boldsymbol{k}_{l} i_{l} \quad, \\
\quad\left|i_{j}\right| \leq i_{\max }, \quad\left|i_{l}\right|=i_{\max } \quad(j=1,2, \cdots, n)
\end{aligned}
$$

ここで， $\boldsymbol{P}_{j}$ は線分上の任意の点を表すべクトル， $\delta_{j l}$ は クロネッカーのデルタである。この線分に原点から垂 線を下ろした際の長さが最も長い線分がトルク領域の 境界として現れる。垂線の長さが最大となるときの式 (8) 第 2 項を $\alpha_{j}$ とおくと, 次式のように表される。

$$
\boldsymbol{P}_{j}=\boldsymbol{k}_{j} i_{j} \pm \boldsymbol{\alpha}_{j},\left|i_{j}\right| \leq i_{\max },(j=1,2, \cdots, n)
$$

すべての相に対しても同様に算出すると, 式(10)に示 す連立方程式が得られる。

$$
\left\{\begin{array}{l}
\boldsymbol{P}_{1}=\boldsymbol{k}_{1} i_{1} \pm \boldsymbol{\alpha}_{1} \\
\boldsymbol{P}_{2}=\boldsymbol{k}_{2} i_{2} \pm \boldsymbol{\alpha}_{2} \\
\vdots \\
\boldsymbol{P}_{j}=\boldsymbol{k}_{j} i_{j} \pm \boldsymbol{\alpha}_{j} \quad, \quad\left|i_{j}\right| \leq i_{\max } \\
\vdots \\
\boldsymbol{P}_{n}=\boldsymbol{k}_{n} i_{n} \pm \boldsymbol{\alpha}_{n}
\end{array}\right.
$$

この連立方程式がトルク領域の境界を表す。つまり， トルク定数ベクトルがすべて平行でない場合, 許容電 流に着目した 2 自由度 $n$ 相球面アクチュエータのトル ク領域は $2 n$ 角形となる。

3 自由度の場合は直線の連立方程式ではなく, 平面 の連立方程式を考える。任意の相を 2 選択し，その 他を定数とする。それにより, トルク座標上で式(11) の平面の式が得られる。

$$
\begin{aligned}
& \boldsymbol{P}_{j k}=\boldsymbol{k}_{j} i_{j}+\boldsymbol{k}_{k} i_{k}+\sum_{l=1}^{n}\left(1-\delta_{j l}\right)\left(1-\delta_{k l}\right) \boldsymbol{k}_{l} i_{l}, \\
& \left|i_{j}\right|,\left|i_{k}\right| \leq i_{\max },\left|i_{l}\right|=i_{\max },(j, k=1,2, \cdots, n \quad, \quad j \neq k)
\end{aligned}
$$

ここで， $\boldsymbol{P}_{j k}$ は平面上の任意の点を表すべクトルである。 2 自由度の場合と同様に, この平面に原点から垂線を おろした際の長さが最も長い平面がトルク領域の境界 として現れる。垂線の長さが最大となるときの式(11) 第 3 項の值を $\boldsymbol{\alpha}_{j k}$ とおくと, 次式のように表される。

$$
\begin{aligned}
& \boldsymbol{P}_{j k}=\boldsymbol{k}_{j} i_{j}+\boldsymbol{k}_{k} i_{k} \pm \boldsymbol{\alpha}_{j k}, \\
& \left|i_{j}\right|,\left|i_{k}\right| \leq i_{\max },(j, k=1,2, \cdots, n \quad, \quad j \neq k)
\end{aligned}
$$

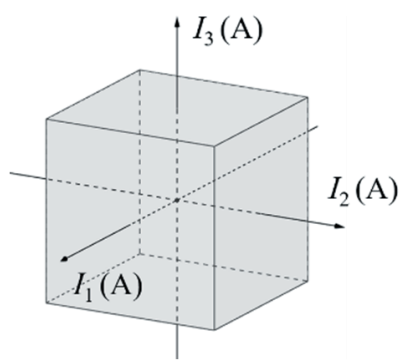

Fig. 6 Current area under allowable current.

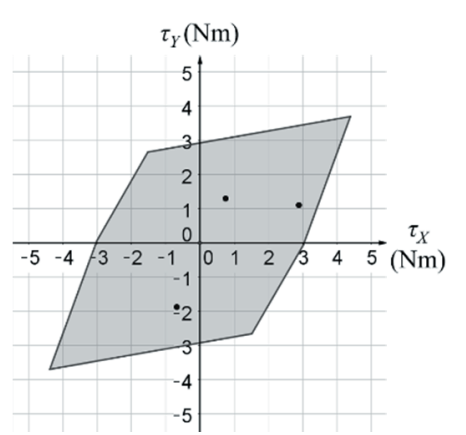

Fig. 7 Torque output area of Eq. (13).

すべての相の組み合わせに対しても同様に算出すると， 式(13)に示す連立方程式が得られる。

$$
\begin{aligned}
& \left\{\begin{array}{l}
\boldsymbol{P}_{12}=\boldsymbol{k}_{1} i_{1}+\boldsymbol{k}_{2} i_{2} \pm \boldsymbol{\alpha}_{12} \\
\boldsymbol{P}_{13}=\boldsymbol{k}_{1} i_{1}+\boldsymbol{k}_{3} i_{3} \pm \boldsymbol{\alpha}_{13} \\
\quad \vdots \\
\boldsymbol{P}_{j k}=\boldsymbol{k}_{j} i_{j}+\boldsymbol{k}_{k} i_{k} \pm \boldsymbol{\alpha}_{j k} \\
\quad \vdots \\
\boldsymbol{P}_{n(n-1)}=\boldsymbol{k}_{n} i_{n}+\boldsymbol{k}_{n-1} i_{n-1} \pm \boldsymbol{\alpha}_{n(n-1)}
\end{array}\right. \\
& \left|i_{j}\right|,\left|i_{k}\right| \leq i_{\max },(j, k=1,2, \cdots, n \quad, \quad j \neq k)
\end{aligned}
$$

この連立方程式がトルク領域の境界を表す。つまり, 3 自由度の場合, トルク領域は多面体となる。トルク定 数ベクトルを組み合わせて得られる平面がすべて平行 でない場合, 3 自由度 $n$ 相の球面アクチュエータのト ルク領域は ${ }_{\mathrm{n}} \mathrm{C}_{2}$ 面体となる。以上で示したように, 卜 ルク領域の形状は 2 自由度の場合は多角形, 3 自由度 の場合は多面体となる。また, 許容電流に着目した卜 ルク領域も, 定電力下でのトルク領域と同様に, トル ク領域は可動子姿勢によって変化する。

\section{3 トルク領域による静特性評価}

このトルク領域を用いて，静特性の評価を行う。本 稿では例として，最小トルクについて扱う。最小トル クはトルク領域の境界上で, 原点と原点に最も短い点 を結ぶベクトルの大きさとする。すなわち，このトル クベクトルの大きさは, その姿勢において任意軸周り 
に発生可能なトルクの大きさとなる。

定電力下におけるトルク領域の最小トルクは，短軸 半径の長さであり, 最も小さい特異值となる。定電力 下における最小トルクは式(14)とする。

$$
T_{\min }= \begin{cases}\sigma_{2} & (2-\mathrm{DOF}) \\ \sigma_{3} & (3-\mathrm{DOF})\end{cases}
$$

許容電流を考慮したトルク領域の場合, 最小トルク は式(15)で表される。

$$
\begin{array}{r}
T_{\min }= \begin{cases}\min \left(\boldsymbol{P}_{j}\right) & (2-\mathrm{DOF}) \\
\min \left(\boldsymbol{P}_{j k}\right) & (3-\mathrm{DOF})\end{cases} \\
j, k=1,2, \cdots, n \quad, \quad j \neq k
\end{array}
$$

\section{4 球面同期アクチュエータの静特性評価}

実際にアクチュエータに対して定電力下，許容電 流下での最小トルクを算出し，比較を行う。例とし て, 著者らが開発している 2 自由度球面アクチュ エータを挙げる[7]。目的はロボット関節への適用で あり, 高卜ルク密度化のために球中心からエア ギャップまでの距離を長くとることができるアウ ターロータ型を採用した初の球面同期アクチュエー タであり, 以降はアクチュエータ $\alpha$ と呼ぶ。アクチュ エータ $\alpha$ の仕様を Table 1 に示し, その基本構造を Fig. 8 に示す。アウターロータ型のため, 球殼状の 可動子が固定子の外側に配置される。可動子の永久 磁石は緯度方向に 22.5 度間隔で極が変わり, 経度方 向は極が一様になるように配置されている。また, 固定子の巻線は 30 度間隔で配置された巻線群が $Z$ 軸周りに 60 度おきに 6 つ配置されている。巻線が施 されたティースは 24 本であるが, 原点対称な位置の 巻線には同相の電流を入力して制御するため, アク チュエータ $\alpha$ のトルク発生式は式(1)において $n=12$ とし， $Z$ 軸周りの成分を除いた式となる。トルク定 数 $K_{X}, K_{Y}$ は Fig. 9 に示寸単相巻線を可動子全域にわ たり, 3 次元有限要素解析を行うことにより求まる。 例として $K_{X}$ の結果を Fig. 10 に示す。

本稿では, 許容電流を $i_{\max }=2.5 \mathrm{~A}$ として最小トルク を算出する。これは電流密度を $5.0 \mathrm{~A} / \mathrm{mm}^{2}$ として算出 された值である。また, 電力は全巻線に許容電流を流 すことが可能な值とし, 電力を式(16)の值とする。

$$
R \sum i^{2}=0.27 \times 2.5^{2} \times 12=20 \mathrm{~W}
$$

ここで, 巻線抵抗 $R$ は $0.27 \Omega$ で算出した。
Table 1 Specification of actuator $\alpha$.

\begin{tabular}{|c|c|}
\hline & Actuator $\alpha$ \\
\hline Diameter of rotor & $97.0 \mathrm{~mm}$ \\
\hline Diameter of stator & $83.2 \mathrm{~mm}$ \\
\hline Thickness of permanent magnets & $3.0 \mathrm{~mm}$ \\
\hline Air gap length & $1.5 \mathrm{~mm}$ \\
\hline Residual magnetic flux density & $0.68 \mathrm{~T}$ \\
\hline Number of coil turns & $50 \mathrm{turns}$ \\
\hline Diameter of coil & $0.8 \mathrm{~mm}$ \\
\hline
\end{tabular}

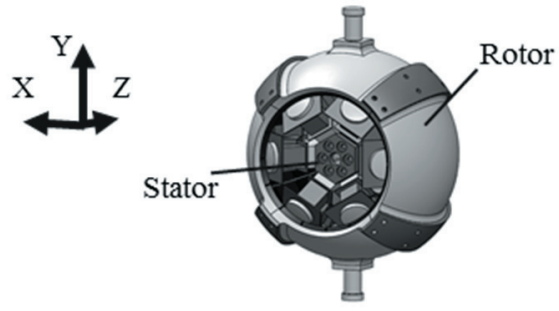

(a) Whole

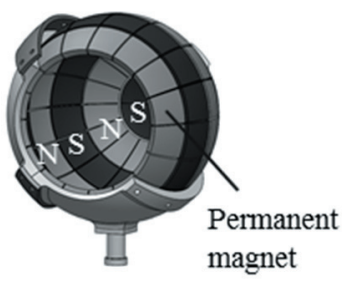

(b) Rotor

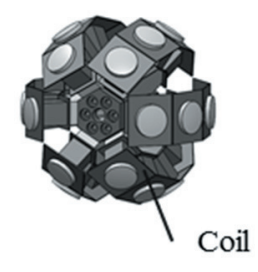

(c) Stator
Fig. 8 Basic structure (Actuator $\alpha$ ).

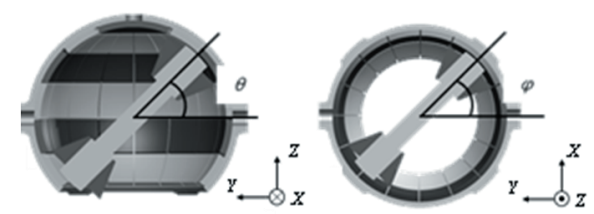

Fig. 9 Simple pole.

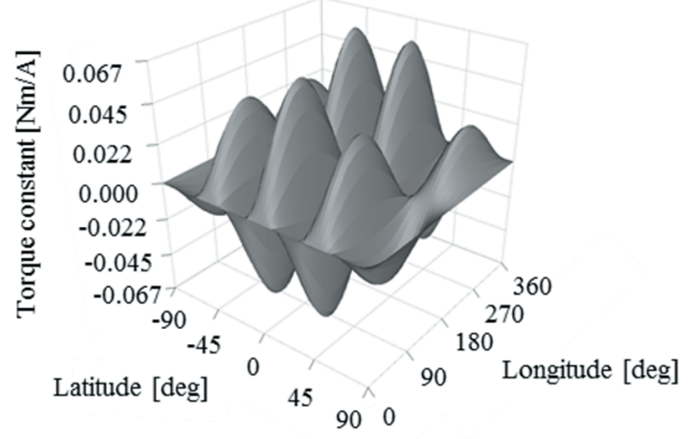

Fig. 10 Torque constant.

本評価手法をアクチュエータ $\alpha$ に適用した際の最小 トルクを Fig. 11 に示寸。アクチュエータ $\alpha$ は経度 60 度毎に周期性があるため, 経度 0 度から 60 度に傾斜角 (緯度) 0 度から 40 度まで姿勢を変化させ, 各姿勢で 

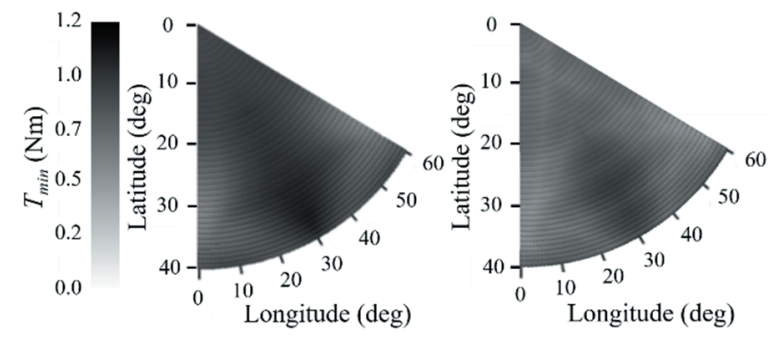

(a)Under constant power

(b)Under allowable current

Fig. 11 Minimum torque.

Table 2 Maximum value of Minimum torque.

\begin{tabular}{|c|c||c|c|}
\hline \multicolumn{2}{|c||}{ Under constant power } & \multicolumn{2}{c|}{ Under allowable current } \\
\hline $\begin{array}{c}\text { Maximum } \\
\text { Value }\end{array}$ & $1.03 \mathrm{Nm}$ & $\begin{array}{c}\text { Maximum } \\
\text { Value }\end{array}$ & $0.89 \mathrm{Nm}$ \\
\hline $\begin{array}{c}\text { Latitude } \\
\text { (deg) }\end{array}$ & $\begin{array}{c}\text { Longitude } \\
\text { (deg) }\end{array}$ & $\begin{array}{c}\text { Latitude } \\
\text { (deg) }\end{array}$ & $\begin{array}{c}\text { Longitude } \\
\text { (deg) }\end{array}$ \\
\hline 36 & $\begin{array}{c}30,90,150 \\
210,270,330\end{array}$ & 30 & $\begin{array}{c}30,90,150 \\
210,270,330\end{array}$ \\
\hline
\end{tabular}

Table 3 Minimum value of Minimum torque.

\begin{tabular}{|c|c||c|c|}
\hline \multicolumn{2}{|c||}{ Under constant power } & \multicolumn{2}{c|}{ Under allowable current } \\
\hline $\begin{array}{c}\text { Minimum } \\
\text { Value }\end{array}$ & $0.51 \mathrm{Nm}$ & $\begin{array}{c}\text { Minimum } \\
\text { Value }\end{array}$ & $0.41 \mathrm{Nm}$ \\
\hline $\begin{array}{c}\text { Latitude } \\
\text { (deg) }\end{array}$ & $\begin{array}{c}\text { Longitude } \\
\text { (deg) }\end{array}$ & $\begin{array}{c}\text { Latitude } \\
\text { (deg) }\end{array}$ & $\begin{array}{c}\text { Longitude } \\
\text { (deg) }\end{array}$ \\
\hline 30 & $\begin{array}{c}0,60,120 \\
180,240,300\end{array}$ & 37 & $\begin{array}{c}0,60,120 \\
180,240,300\end{array}$ \\
\hline
\end{tabular}

の最小トルクを算出した結果である。最小トルクが最 大, 最小となる姿勢をそれぞれ Table 2, Table 3 に示す。

Table 2 より, 固定子巻線が配置されているラインに 沿って最小トルクが大きい姿勢が集中している。一方 で, Table 3 より直下に巻線が存在しない姿勢で最小ト ルクが小さくなっていることがわかる。これは，巻線 が配置されているライン上の姿勢の方が, トルクに寄 与できる巻線が多いためと考えられる。

また，定電力下における最小トルクは，許容電流に 着目した場合の最小トルクよりも全域で大きいことが わかる。これは，定電力下では，巻線抵抗によって消 費される電力といら制限のみを考えており, 各巻線に 許容電流以上の電流を印加しているためである。本来 は固定子巻線の絶縁被膜の保護なじの観点から, 許容 電流の制限を定める必要があり，許容電流に着目した 最小トルクが定電力下における最小トルクよりも小さ くなる場合が存在する。

したがって, 巻線の線径や泠却条件が異なる球面ア クチュエータの比較には, アクチュエータ自体の許容 電流に着目したトルク領域も用いる必要があると考え られる。

\section{5 結言}

本稿では球面アクチュエータ自体の許容電流に着 目したトルク領域による評価方法を提案した。これに より, 定電力下におけるトルク領域法では考慮できて いなかった球面アクチュエータ自体の制限を用いた評 価が可能となった。

しかし，鉄心を用いたアクチュエータではコギング トルクが発生し，トルク領域が平行移動する。実際に 出力するトルクはコギングトルクの影響を受けるため, コギングトルクも考慮する必要があると考える。

\section{参考文献}

[1] 武田行生, パラレルマニピュレータの機構と特性, 日本 ロボット学会誌, Vol. 30, No. 2, pp. 124-129 (2012)

[2] H. Asada, T Kaneda, and R. Reddy, Design Concept of Direct-Drive Manipulators Using Rare-Earth DC Torque Motors, Proceeding of 11th ISIR, pp. 629-636 (1981)

[3] 平田勝弘, 次世代アクチュエータ原理と設計法, 科学技 術出版, 2013

[4] K. Kahlen, I. Voss, C. Priebe and R. W. De Doncker, Torque Control of a Spherical Machine with Variable Pole Pitch, IEEE Transactions on Power Electronics, Vol. 19, No. 6, pp. 1628-1634 (2004)

[5] H. Son and Kok-Meng Lee, Open-Loop Controller Design and Dynamic Characteristics of a Spherical Wheel Motor, IEEE Transactions on Industrial Electronics, Vol. 57, No. 10, pp. 3475-3482 (2010)

[6] B. van Ninhuijs, J. W. Jansen, B. L. J. Gysen, and E. A. Lomonova, Topology Comparison of Slotless Permanent Magnet Semispherical Actuators, IEEE Transactions on Magnetics, Vol. 50, No. 11 (2014)

[7] Y. Sakaidani, K. Hirata, N. Niguchi and S. Maeda, Experimental verification of feedback control of a 2-DOF spherical actuator, IEEE Transactions on Magnetics, Vol. 50, No. 11 (2014)

[8] 西浦悠介, 平田勝弘, 堺谷洋, 新口昇, 3 自由度アウター ロータ型電磁球面アクチュエータに関する研究, 電気学 会論文誌 D, Vol. 136, No. 3(2016), pp.232-237

[9] A. Bhatia, M. Kumagai and R. Hollis, Six-Stator spherical induction motor for balancing mobile robots, 2015 IEEE International Conference on Robotics and Automation (ICRA), pp. 226-231

[10] 矢野 智昭, 多面体にもとづく球面ステッピングモータ の分類, 電気学会研究会資料, IEEJ LD 2009, LD09055, (2009)

[11] 高原一晶, 平田勝弘, 新口昇, 西浦悠介, 堺谷洋, 藤原 優文，多自由度球面同期アクチュエータの定電力下にお ける静特性評価手法の提案, 電気学会論文誌 D, Vol. 136, No. 11(2016), pp.907-912 